\title{
Synthesis and Optical Properties of Near-Infrared (NIR) Absorbing Azo Dyes
}

\author{
Sharad Patil ${ }^{1,3 *}$, Amol Choudhary ${ }^{2,3}$, N Sekar $^{3}$, Pratik Pipliya ${ }^{1}$ and Pooja Rathod ${ }^{1}$ \\ ${ }^{1}$ Department of Chemistry, Uka Tarsadia University, India \\ ${ }^{2} A T$ Inks, R\&D Centre, India
}

${ }^{3}$ Department of Dyestuff Technology, Institute of Chemical Technology, India

Submission: February 25, 2019; Published: March 27, 2019

*Corresponding author: Sharad Patil, Department of Chemistry, Uka Tarsadia University, Bardoli, Gujarat, India

\begin{abstract}
In this work, we have developed an efficient and simple protocol for the synthesis of novel A- $\pi$-D- $\pi$-A NIR azo dyes. The near infrared absorbing azo dyes were synthesized by using 2-hydroxy-1, 4 naphthoquinone (Lawsone) and different substituted aromatic primary amines. Furthermore, author developed push-pull chromophores of A- $\pi-D-\pi-A$ type containing an electron-withdrawing azo core, phenazine moieties, and a hydroxyl group as electron donor. The benzo [a] quinoxalino [2,3-i] phenazin-5-ol moiety was introduced to make the system planer as well as to increase the $\pi$-conjugation. The optical properties of these dyes were studied in $\mathrm{N}, \mathrm{N}$-dimethylformamide (DMF).
\end{abstract}

Keywords: NIR Absorbing azo dyes; 2-hydroxy-1; 4 Naphthoquinone; Lawsone; Optical properties; Phenazine core

\section{Introduction}

In 1856, William Henry Perkin accidentally discovered the world's first commercially successful synthetic dye. Dyes are defined as coloured organic or inorganic compounds, mixtures, complexes or substances that once applied to the fibers/substrate, it imparts a permanent color to the fiber/substrate. This is able to resist fading upon exposure to sweat, light, water and many chemicals, including oxidizing agents and microbial attack. Over 10,000 synthetic dyes were developed and used in manufacturing by the end of the $19^{\text {th }}$ century. Azo dyes are a class of compounds containing a double bond and, due to their ability to absorb visible to Near-Infrared (NIR)N=Nlight and ease of synthesis, have been extensively used in the textile, fiber, leather, paint and printing industries for more than a century. The azo group is substituted with benzene or naphthalene groups, which can contain many different substituents, such as chloro $(-\mathrm{Cl})$, methyl $\left(-\mathrm{CH}_{3}\right)$, nitro $\left(-\mathrm{NO}_{2}\right)$, amino $\left(-\mathrm{NH}_{2}\right)$, and hydroxyl $(-\mathrm{OH})$, carboxyl $(-\mathrm{COOH})$, which give different types of azo dyes. Azo dyes accounts for the majority (more than 3000 different varieties) of all textile dyestuffs produced because of the ease and cost effectiveness of their synthesis, their stability and the variety of colors available compared to natural dyes. They are extensively used in the textile, paper, food, leather, cosmetics and pharmaceutical industries [1$3]$.
Azo colorant represents the greatest production volume in dyestuff chemistry due to simplicity of coupling reaction, adaption to the needs of most diverse applications such as textile dying, colouring of plastics and polymer, in liquid crystal displays (LCD), optical data storage, non-linear optics, biological and medical field and advanced application in organic synthesis [4-6]. Azo chromophores have versatile applicability ranging from textile dyeing [7], leather dyeing [8], coloring of plastics and polymer [9] to advanced applications such as liquid crystal displays [10], biological and medical studies and advanced application in the organic synthesis [11]. Also, they contribute greatest production volume of the dyestuff industry due to simplistic mode of their synthesis with high yield. The infrared wavelength ranges of the electromagnetic spectrum cover the area between the visible region and the microwave region. The infrared radiation spectrum is generally accepted and can be sub classified into the near, medium and far infrared regions. An important challenge in creating molecules with desired optical properties lies in achieving a well- defined architecture while maintaining adequate electron density throughout the whole molecule [12]. Organic materials with intense absorptions in the near - IR region (i.e 750-1300nm) are particularly important in number of applications including thermal i.e. imaging, optical data storage, automatic identification, etc. NIR absorbing dyes have been attracting increasing interest 
due to the rapid progress achieved in their high technology applications.

In this region, infrared radiation provides sufficient energy to the NIR dyes, which impart a $\pi \rightarrow \pi *$ transition of electrons within dye chromophore molecules. Despite the enormous synthetic versatility of azo dyes, which accounts for representing $50-70 \%$ of all commercially available dyes, little effort has been devoted to bring their absorption into the long wavelength region and only a few examples of NIR absorbing azo dyes have till now been disclosed [13-14]. Near-infrared absorbing dyes have attracted significant interest for their uses in the development of functional materials for high-technology end uses. Considerable interest is evinced in recent years in the design of near infrared absorbing organic azo dyes. They find manifold applications in the high technology areas such as dye sensitised solar cells (DSSCs) [15], laser optical storage systems [16], clear coatings [17], organic photovoltaics [18], greenhouse claddings [19], molecular switches [20], NIR - active materials [21], colorimetric sensors [22], mesomorphic [23], solvatochromic [24-26], and electrochemical materials [27] and surface relief grating (SRG)forming azo polymer films [28], laser-printing systems, laser filters, photography, photonics, and in telecommunication devices operating at wavelengths in the NIR region [29].

The planar structure of phenazine with a heterocyclic pyrazine nucleus and a fully conjugated aromatic -system imparts to that special optical and redox properties. The optical properties give it functional for applications in molecular imaging as fluorescent tracers and stains for sub-cellular components and biological events. Highly electron-rich and redox-active molecules like phenazines might be functional for preparation of organic materials that includes donor- $\pi$-acceptor design. Pyrazine compounds are electron-deficient species. Hence, they are used in the design of n-type organic semiconductors examples are pyrazino quinoxaline derivatives, hexaazatriphenylenes, diquinoxalino, phenazine, and quinoxalinophenanthro phenazine [30]. Richards et al. have shown that the pyrazinacene are good candidates as materials Richards for organicetal thin film transistors as shown in the Figure 1 [31]. The existence of a donor- $\pi$-acceptor (D- $\pi$ -A) alternating structure has been proved to be an efficient way to reduce band gap energies of conjugated molecules. Since the phenazine core consists of the electron withdrawing pyrazine ring which might be an excellent charge acceptor. Chemical structure of pyrazinacenes for organic thin film transistors. Romanyuk et al. [32] has reported azo derivatives of 2-hydroxy-1, 4 naphthoquinones 5 as shown in Figure 2 [32]. There are no further reports in the use of 2-hydroxy-1, 4-naphthoquinone in the synthesis of azo colorants. It is known that the molecule with a quinoid fragment shows keto-enol tautomerism when a hydroxyl group is presenting adjacent to one of the quinoid carbonyl groups: the p-quinoid structure can transform into an o-quinoid or dihydro structure [33].
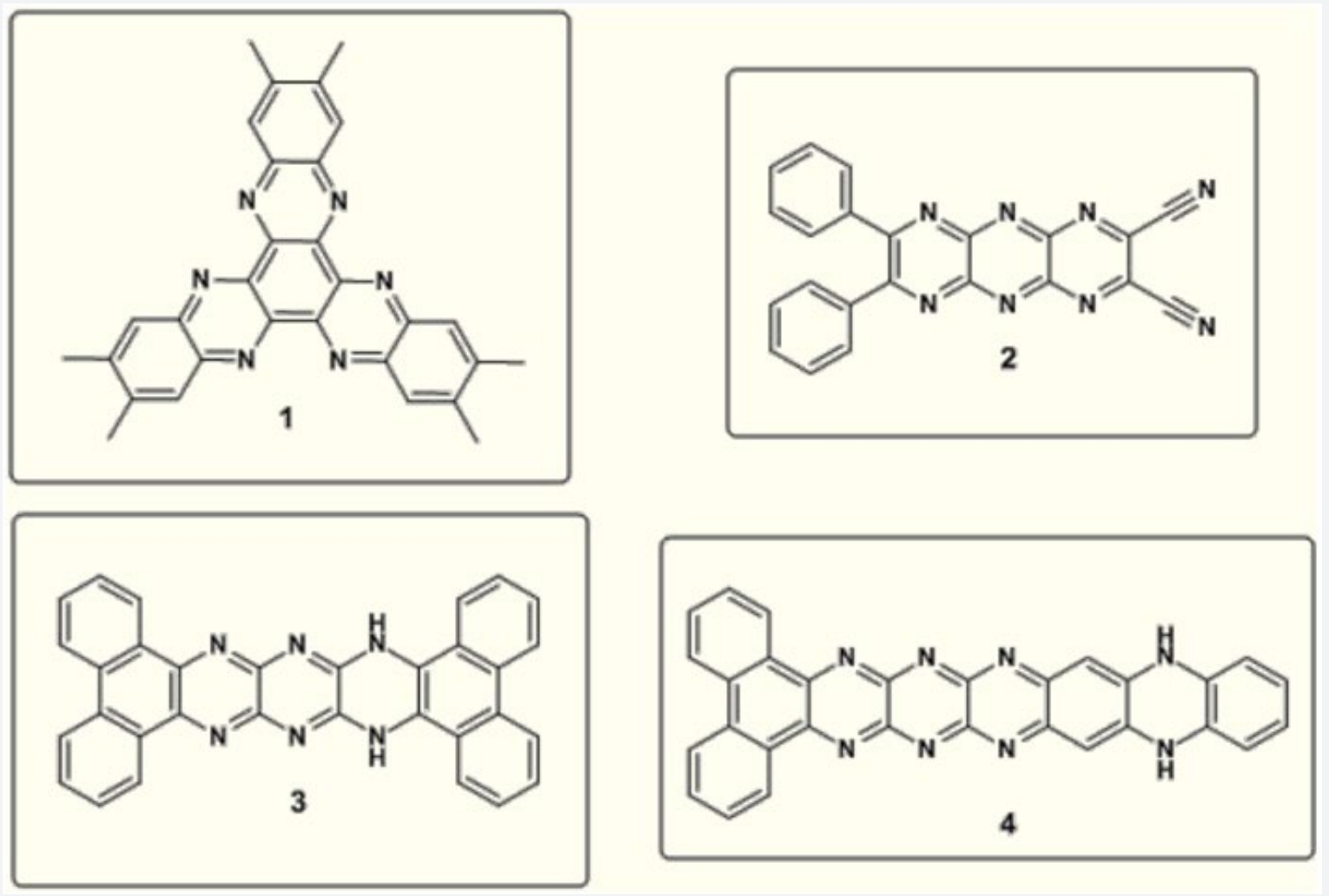

Figure 1: Chemical structure of pyrazinacenes for organic thin film transistors. 
<smiles>Oc1c(/N=N/c2ccccc2)c2nc3ccccc3nc2c2ccccc12</smiles><smiles>O=[N+]([O-])c1ccc(/N=N/c2c(O)c3ccccc3c3nc4ccccc4nc23)cc1</smiles><smiles>Cc1ccc(/N=N/c2c(O)c3ccccc3c3nc4ccccc4nc23)cc1</smiles>

$\lambda_{\max }=465-475 \mathrm{~nm}$

Figure 2: Reported azo derivatives of lawsone [6-8].

The reactions of 2-hydroxy-1, 4-naphthoquinone in the synthesis of azo colorants for NIR-absorbing dyes have been explored in our previous work. Three different kinds of Near Infra-

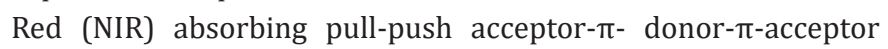
(A- $\pi-D-\pi-A) ~ V-s h a p e$ chromophoric dyes have been synthesized. These dyes are architect by doing substitution with 5-hydroxy and 6-arylazonium on the benzo [a] naphtho [2,3-h] phenazine Dione core. Phenazine and anthraquinone moieties were envisaged in a single molecule with a view to enhance the photophysical properties in NIR region as shown in Figure 3 [34]. This work is aimed at synthesising novel molecules containing both phenazine and azo cores were envisaged in a single molecule with a view to enhance the photophysical properties in the NIR region. In this study, we have extended our contribution to synthesis NIR absorbing dyes [12-14] as shown in Figure 4.

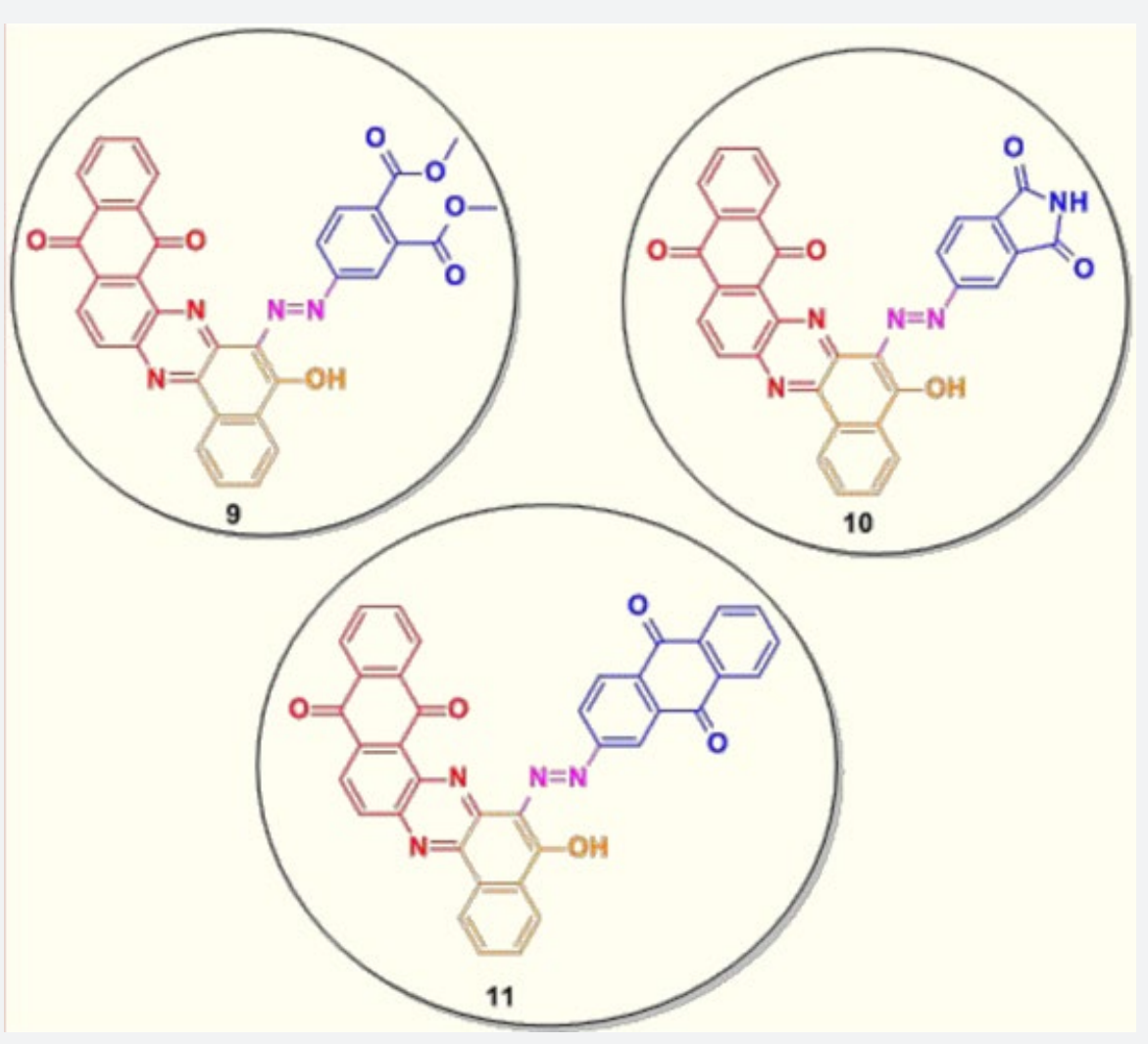

Figure 3: Structures of the dyes [9-11]. 


\section{Current Trends in Fashion Technology \& Textile Engineering}

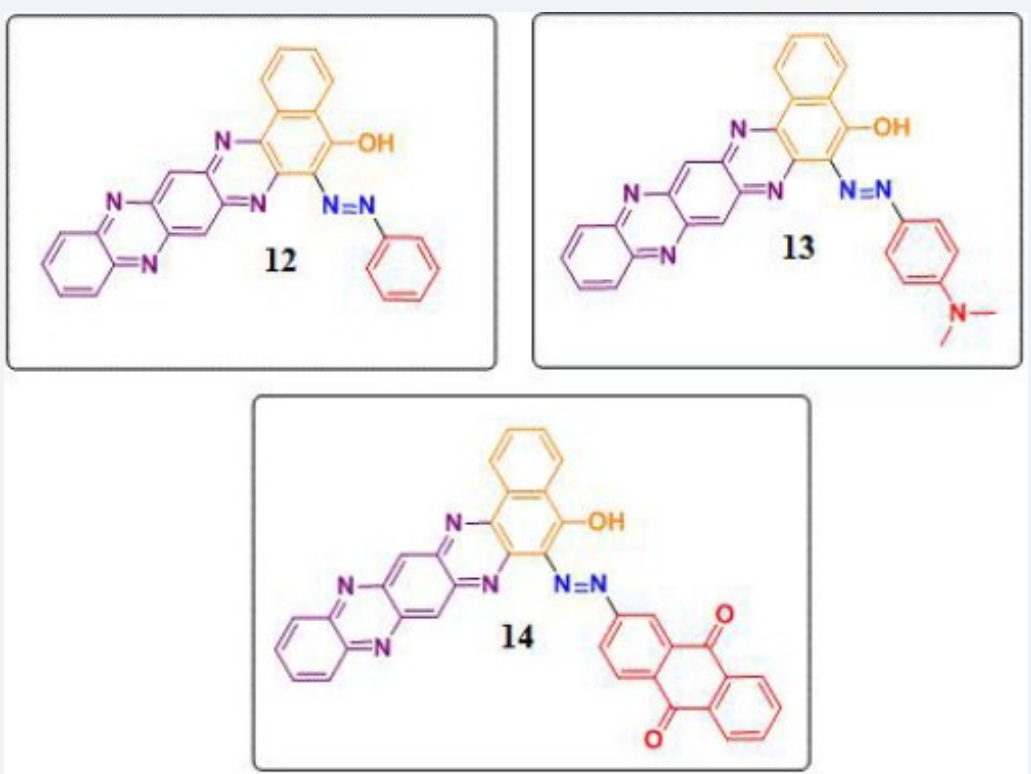

Figure 4: Structures of the Near-IR absorbing dyes [12- 14].

\section{Result and Discussion}

\section{Synthesis strategy}

In the present study, the use of 2-hydroxy 1, 4-naphthoquinone (Lawsone) 5 coupling components and diazo components in the synthesis of azo disperse dyes followed by condensation with o-phenylenediamine OPDA to obtain the desired NIR absorbing azo dyes [12-14]. In this context, author have extended our contribution to synthesis of three different kind of Near Infra-Red (NIR) absorbing pull-push acceptor- $\pi$-donor- $\pi$ acceptor (A- $\pi-D-$ $\pi-A)$ chromophoric dyes. The NIR absorbing dyes [12-14] were synthesised from derivatives of 2-hydroxy-3-(phenyldiazenyl) naphthalene-1, 4-dione [18-20] and 2, 3- diaminophenazine core [21] (Figure 5).

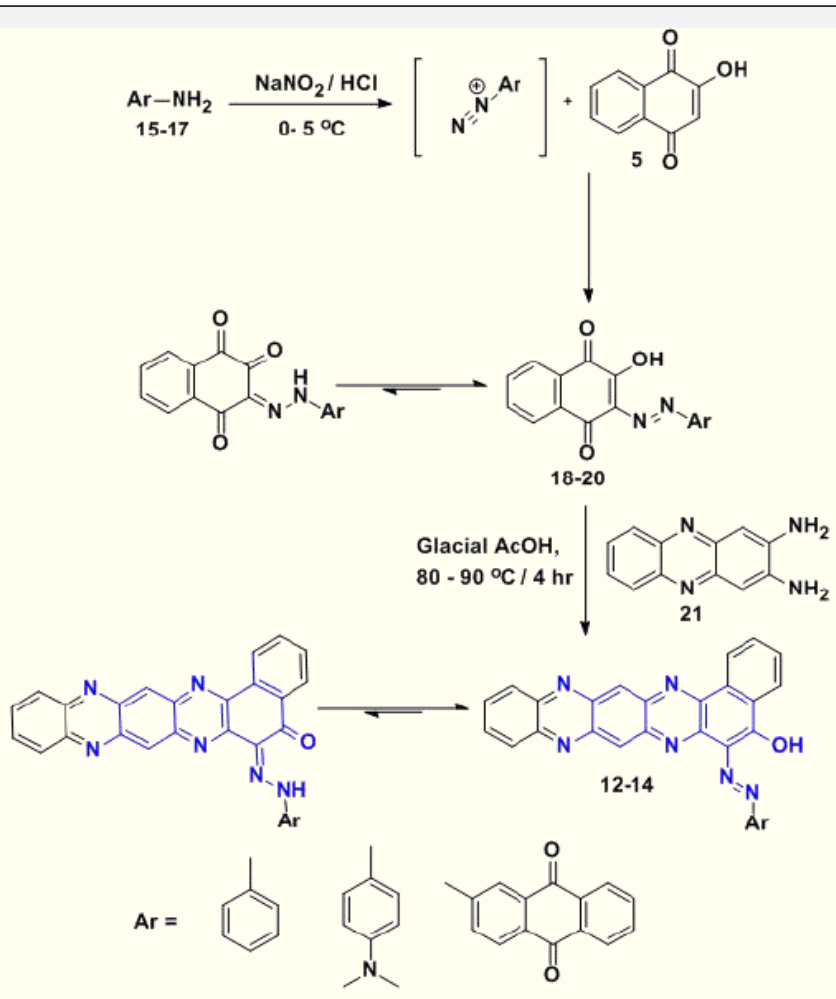

Figure 5: Schematic representation of NIR azo dyes [12-14]. 


\section{Current Trends in Fashion Technology \& Textile Engineering}

The scaffold of phenazine, N, N-dimethylaniline and anthraquinone moieties was envisaged in a single molecule with a view to enhance the photophysical properties in NIR region. The UV-Vis absorption spectra of synthesized azo-azine dyes have been studied. The intermolecular interaction occurring in solvents of differing polarities as well in solution of different $\mathrm{pH}$ have been studied. The structures of the dyes are given in Figure 4. Synthetic route for the dyes and their intermediates are depicted in Figure 5.

\section{Optical properties}

The UV-Visible absorption spectra of the dyes [18-20, 1214] measured in $\mathrm{N}, \mathrm{N}$-dimethylformamide (DMF). These dyes do not show solvatochromism significantly. The dyes [18-20] were absorption at 439-490 nm (Figure $6 \&$ Table 1). The redshifted absorptions owing to the $\pi$-conjugation framework present in these dyes. The peak close to at $620-710 \mathrm{~nm}$ due to the intramolecular charge transfer transition (ICT) between donoracceptor pair (Figure 7, Table 1).

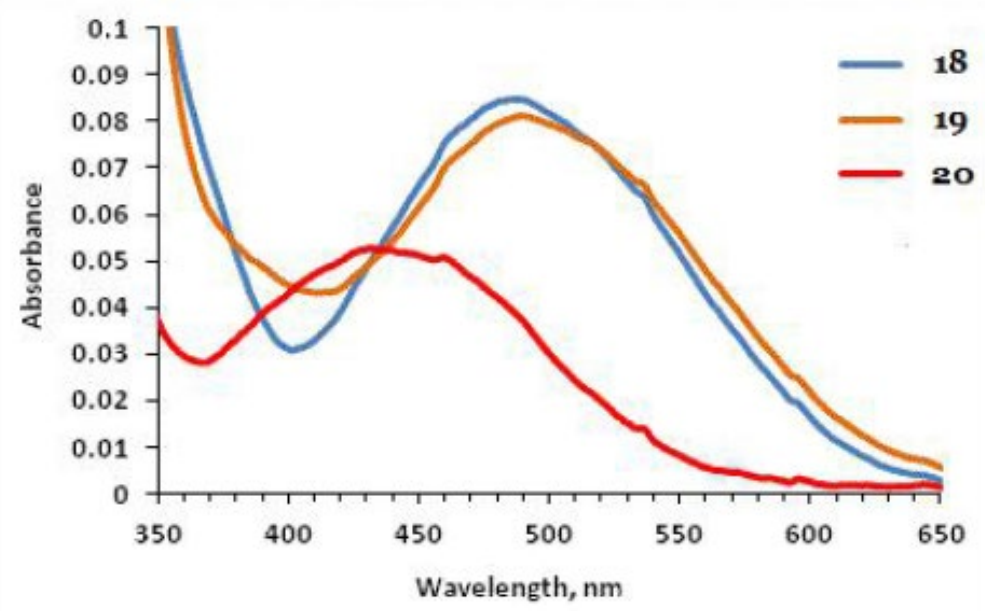

Figure 6: Visible absorption of the dyes [18-20] in DMF solvent.

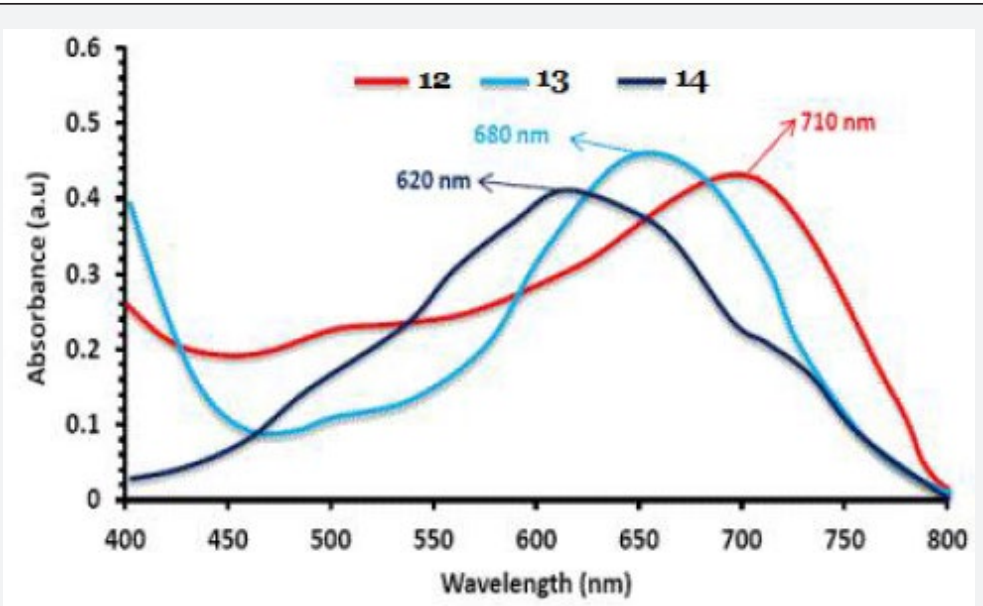

Figure 7: Visible absorption of the dyes [12-14] in DMF solvent.

Table 1: Visible absorption of the dyes [18-20,12-14] in DMF solvent.

\begin{tabular}{|c|c|c|c|}
\hline Dye & $\lambda_{\max }(\mathrm{nm})$ & $(\log \varepsilon)$ & $\varepsilon_{\max }\left(\mathrm{dm}^{3} \mathrm{~mol}^{-1} \mathrm{~cm}^{-1}\right)$ \\
\hline 18 & 487 & 4.93 & 84830 \\
\hline 19 & 490 & 4.91 & 81275 \\
\hline 20 & 439 & 4.72 & 52260 \\
\hline 12 & 620 & 4.6 & 40000 \\
\hline 13 & 710 & 4.63 & 43000 \\
\hline 14 & 680 & 4.69 & 49000 \\
\hline
\end{tabular}




\section{Experimental Sections}

\section{Materials and Methods}

The materials and solvents used in the present work were pure and laboratory prepared. All the commercial chemical reagents and spectroscopic grade solvents were procured from S. D. Fine chemicals private limited Mumbai. The solvents and reagents were used as received without further purification. The reactions were monitored on silica gel aluminium based plates kisel gel 60 F254 Merck, India. The synthesized dyes were purified by recrystallization technique. Spectronic Genesys 2 UV-Visible spectrophotometer was used for UV-Vis absorption spectra. Perkin-Elmer Spectrum 100 FT-IR spectrometer was used for IR spectral analysis and VXR $300 \mathrm{MHz}$ NMR was used for 1H NMR with TMS as internal standard. Finnigan mass spectrometer was used for mass spectra analysis and technique used was Electro Ionisation (EI) technique for low molecular weight.

\section{General experimental procedure of the Azo dyes [18-} 20]

The aromatic primary amines (5g) was partially dissolved in conc. $\mathrm{HCl}(5 \mathrm{~mL})$ in $80 \mathrm{~mL}$ water and cooled to $0-5^{\circ} \mathrm{C}$. The solution of $\mathrm{NaNO}_{2}(2 \mathrm{~g})$ in $5 \mathrm{~mL}$ water was added slowly to the reaction mixture and the reaction temperature was kept below $5{ }^{\circ} \mathrm{C}$. The resulting aryl diazonium salt was added to the alkaline solution of Lawson $(5 \mathrm{~g})$ and $\mathrm{NaOH}(1.15 \mathrm{~g})$ in $60 \mathrm{~mL}$ of water and reaction temperature was maintained $0-5{ }^{\circ} \mathrm{C}$. The reaction mass was stirred for 2.0-2.5 h, after which mixture was acidified with dil. $\mathrm{HCl}$. The precipitate out and filtered, washed with water and then aqueous $\mathrm{EtOH}$ and dried.

\section{General experimental procedure of the Azo-Phenazine dyes [12-14]}

Diketo-azo derivatives [18-20] and diaminophenazine [21] were mixed together then refluxed in acetic acid for $4 \mathrm{~h}$. The $\mathrm{AcOH}$ was removed under reduced pressure in a rotary evaporator and water was added to the residue. The precipitate out and filtered, washed with water and then aqueous ethanol and dried.

\section{General experimental procedure of the 3-Diaminophenazine (21)}

Finally, powdered o-phenylenediamine $(54.0 \mathrm{~g}, 0.5 \mathrm{~mol})$ was dissolved in conc. hydrochloric acido $(83.3 \mathrm{ml})$ and distilled water (2.5L). A filtered solution of ferric chloride $(400 \mathrm{~g})$ in $(750 \mathrm{ml})$ water was added slowly and the mixture was stirred mechanically. After standing overnight at room temperature the red-brown colored crystalline product was filtered off, washed with cold dilute $0.3 \mathrm{~N} \mathrm{HCl}$ until free from ferric ions, then dissolved in hot water $(2.5 \mathrm{~L}), 2$, 3-diaminophenazine was precipitated by the addition of a concentrated solution of potassium hydroxide. The product was filtered off, washed with water and dried at 100-110 ${ }^{\circ} \mathrm{C}$. The strongly alkaline filterate was heated and acidified $(\mathrm{pH}$ 4.5) with glacial acetic acid. After cooling, 2-amino-3-hydroxy phenazine was collected, washed with water and dried at 100-110 ${ }^{\circ} \mathrm{C}$. The crude products used without further purification.

\section{Characterization}

(Figure 8) Yield 72\%; Melting point (measured) $>300^{\circ} \mathrm{C}$. FT-IR $\left(\mathrm{KBr}, \mathrm{cm}^{-1}\right)=3057(\mathrm{O}-\mathrm{H}), 1630(\mathrm{C}=\mathrm{N}), 1589$ (arom.), 1534 (arom. ring). ${ }^{1} \mathrm{H}-\mathrm{NMR}$ (DMSO, 500MHz) $=\delta 8.30-8.24(\mathrm{~m}, 4 \mathrm{H}$, aromatic), 8.26-8.16 (m, 3H, aromatic), 7.92-7.76 (m, 8H, aromatic), $5.2(1 \mathrm{H}$, s, $\mathrm{OH})$.

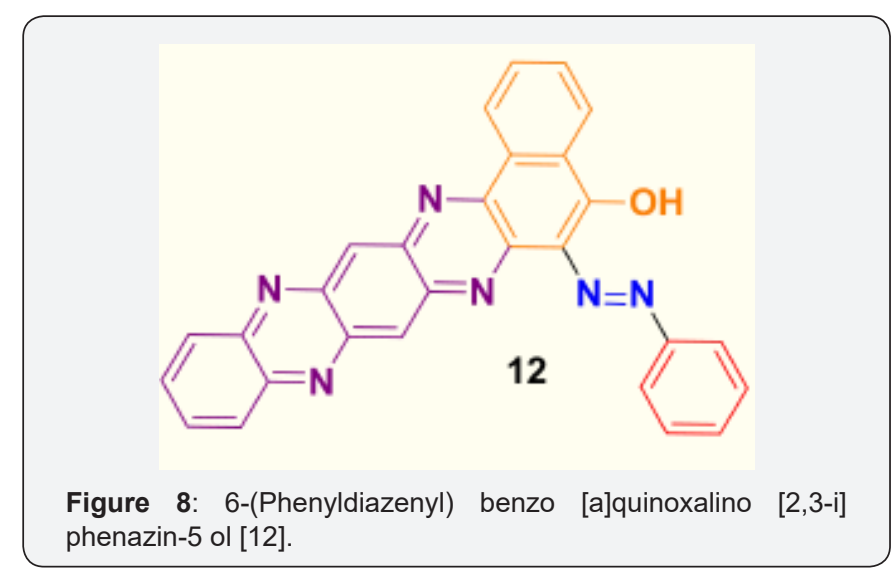

(Figure 9) Yield 80\%; Melting point (measured) $>300^{\circ} \mathrm{C}$. FT-IR $\left(\mathrm{KBr}, \mathrm{cm}^{-1}\right)=3169(\mathrm{OH}), 1674(\mathrm{C}=\mathrm{N}), 1633$ (arom.), 1514 (arom. ring). ${ }^{1} \mathrm{H}-\mathrm{NMR}$ (DMSO, $\left.500 \mathrm{MHz}\right)=\delta 8.25(\mathrm{~s}, 2 \mathrm{H}$, aromatic), 8.23$7.78\left(\mathrm{~m}, 12 \mathrm{H}\right.$, aromatic), 3.86(s,6H, $\left.\mathrm{CH}_{3}-\mathrm{N}-\mathrm{CH}_{3}\right), 6.18(1 \mathrm{H}, \mathrm{s}, \mathrm{OH})$.

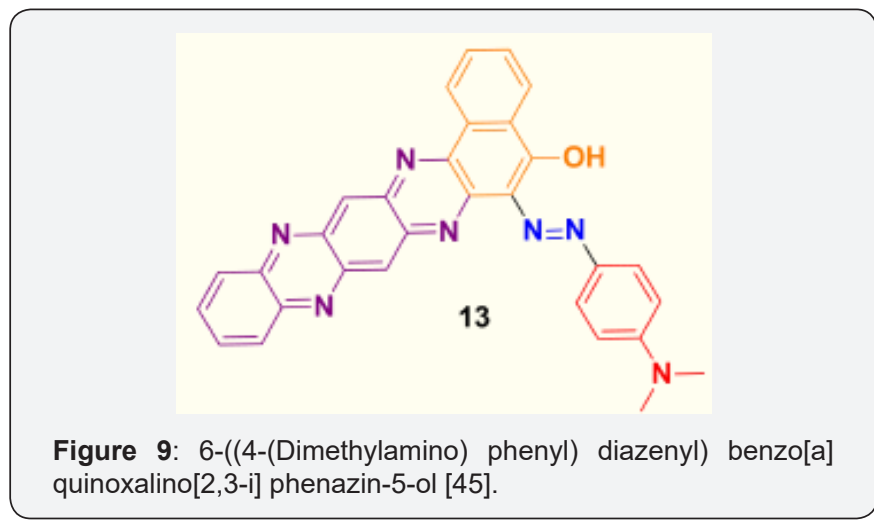

(Figure 10) Yield 67\%; Melting point (measured) $>300$ ${ }^{\circ} \mathrm{C}$. FT-IR $\left(\mathrm{KBr}, \mathrm{cm}^{-1}\right)=3059(\mathrm{O}-\mathrm{H}), 1629(\mathrm{C}=\mathrm{N}), 1590$ (arom.), 1529 (arom. ring). ${ }^{1} \mathrm{H}-\mathrm{NMR}$ (DMSO, $\left.500 \mathrm{MHz}\right)=\delta 8.304(\mathrm{~s}, 2 \mathrm{H}$, aromatic), 8.292- (m, 12H, aromatic), 7.77-7.76 (m, 3H, aromatic), $5.2(1 \mathrm{H}, \mathrm{s}, \mathrm{OH})$.

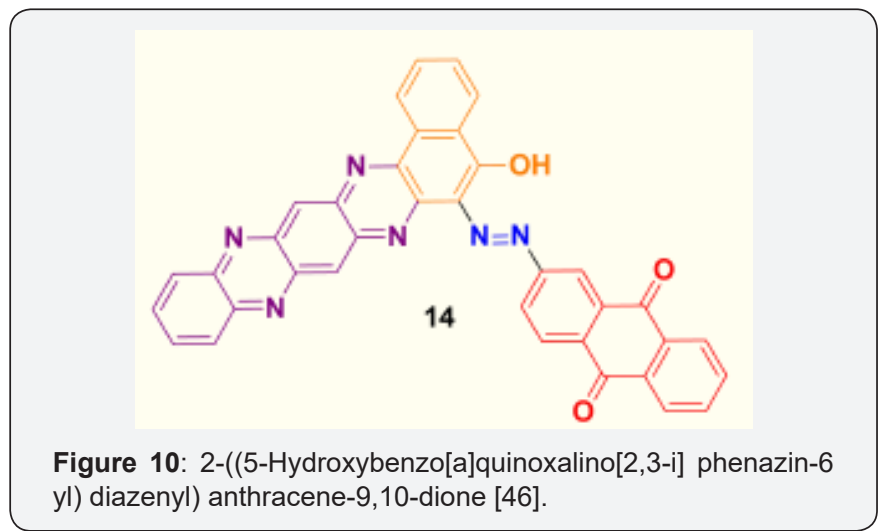




\section{Current Trends in Fashion Technology \& Textile Engineering}

\section{Conclusion}

Azo colorants represent the greatest production volume in dyestuff chemistry due to simplicity of coupling reaction, adaption to the needs of most diverse applications such as textile dying, colouring of plastics and polymer, in liquid crystal displays (LCD), optical data storage, non-linear optics, biological and medical field and advanced application in organic synthesis. In this context, author have designed and developed push-pull chromophores of A- $\pi$-D- $\pi$-A type containing an electron-withdrawing azo core, phenazine moieties, and a hydroxyl group as electron donor. The benzo[a]quinoxalino[2,3-i] phenazin-5-ol moiety was introduced to make the system planer as well as to increase the n-conjugation. These synthesised chromophores were confirmed by FT-IR, ${ }^{1} \mathrm{H}$ -NMR, 13C-NMR and MS spectral analysis. The optical properties of these dyes were studied in DMF. NIR absorbing dyes have been considered in numerous recent hi-tech applications like optical device, optical recordings, laser printings, laser thermal writing displays, infrared photography and biological/medical applications. In optoelectronic application areas, especially, NIR absorbing dyes are being developed and new structural designs of the dye chromophore molecules are being studied. Azo dyes form the most important class of organic dyes. However, from the point of view their carcinogenicity they are suspect. Therefore, research of the dyes is aimed at development of new type of chromophores. The NIR azo dyes may probably prove to be a solution to this problem.

\section{References}

1. Yan Li, Brian O Patrick, David Dolphin (2009) Near-Infrared Absorbing Azo Dyes: Synthesis and X-ray Crystallographic and Spectral Characterization of Monoazopyrroles, Bisazopyrroles, and a Boron Azopyrrole Complex. J Org Chem 74(15): 5237-5243.

2. Singh RP, Singh PK, Singh RL (2017) Role of Azoreductases in Bacterial Decolorization of Azo Dyes. Curr Trends Biomedical Eng \& Biosci 9: $1-3$

3. Telke A, Kalyani D, Jadhav J, Govindwar S (2008) Kinetics and Mechanism of Reactive Red 141 degradation by a Bacterial Isolate Rhizobium radiobacter. Acta Chim Slov 55: 320-329.

4. Yasin Arslanoglu, Altug Mert Sevim, Esin Hamuryudan, Ahmet Gul (2006) Near-IR absorbing phthalocyanines. Dyes and Pigments 68(23): $129-132$.

5. Saratale RG, Saratale GD, Chang JS, Govindwar SP (2011) Bacterial decolorization and degradation of azo dyes. Journal of the Taiwan Institute of Chemical Engineers 42(1): 138-157.

6. Gregory P In: Hunger K (2002) Synthetic Applications of 1,3-Dipolar Cycloaddition Chemistry toward Heterocycles and Natural Products. Industrial dyes: chemistry, properties and applications. Weinheim: Wiley-VCH: pp. 543-85.

7. Bamfield P, Hutchings MG (2010) Chromic phenomena: technological applications of colour chemistry. $2^{\text {nd }}$ (Edn.), Cambridge: RSC; Electrochemistry of Nanomaterials.

8. Koh J, Greaves AJ (2001) Synthesis and application of an alkali-clearable azo disperse dye containing a Fluor sulfonyl group and analysis of its alkali-hydrolysis kinetics. Dyes and Pigments 50: 117-126.
9. Vijayaraghavan R, Vedaraman N, Surianarayanan M, MacFarlane DR Talanta (2006) Synthesis and application of an alkali-clearable azo disperse dye containing a fluorosulfonyl group and analysis of its alkali-hydrolysis kinetics 69: 1059-1062.

10. Carolin Fleischmann, Melanie Lievenbrück, Helmut Ritter (2015) Polymers and Dyes: Developments and Applications 7: 717-746.

11. Moustafa A Gouda, Hadeer Fakhr Eldien, Margret M Girges, Moged A Berghot (2016) Synthesis and antitumor evaluation of thiophene based azo dyes incorporating pyrazolone moiety. Journal of Saudi Chemical Society 20(2): 151-157.

12. Nejati K, Rezvani Z, Seyedahmadian M (2009) The synthesis, characterization, thermal and optical properties of copper, nickel, and vanadyl complexes derived from azo dyes. Dyes and Pigments 83(3): 304-311.

13. Dong M, Babalhavaeji A, Hansen MJ, Kalman L (2015) Red, far-red, and near infrared photo switches based on azonium ions. G A. Woolley Chem 65: 12981-12984.

14. Salvador MA, Reis LV, Almeida P (2008) Delocalized cationic azo dyes containing a thiazole moiety. Santos PF. Tetrahedron 64: 299-303.

15. Mikroyannidi J, Tsagkournos D, Sharma S, Kumar A, Vijay Y, et al. (2010) Efficient bulk heterojunction solar cells based on low band gap bisazo dyes containing anthracene and/or pyrrole units. Sol Energy Mater Sol Cells 94(12): 2318-2327.

16. Fuxin H, Yiqun W, Donghong G, Fuxi G (2005) Synthesis, spectroscopic and thermal properties of nickel (II) eazo complexes with blueblueviolet light wavelength. Dyes and Pigment 66: 77-82.

17. Knischka R, Lehmann U, Stadler U, Mamak M, Benkhoff J (2009) Novel approaches in NIR curing technology. Prog Org Coat 64(2-3): 171-174.

18. Sekar N, Raut R, Umape P (2010) Near Infrared absorbing ironcomplexed colorants for photovoltaic applications. Mat Sci Eng B 168(1-3): 259-262.

19. Lamnatou C, Chemisana D, Renew (2013) Solar radiation manipulations and their role in greenhouse claddings: Fresnel lenses, NIR- and UVblocking materials. Sust Energy Rev 18: 271-287.

20. Li N, Lu J, Li H, Kang E (2011) Nonlinear optical properties and memory effects of the azo polymers carrying different substituents. Dyes and Pigment 88(1): 18-24.

21. Salvador M, Almeida P, Reis L, Santos P (2009) Near-infrared absorbing delocalized cationic azo dyes. Dyes and Pigment 82(2): 118-123.

22. Kaur P, Sareen D (2011) The synthesis and development of a dualanalyte colorimetric sensor: Simultaneous estimation of $\mathrm{Hg}^{2+}$ and $\mathrm{Fe}^{3+}$. Dyes and Pigment 88(3): 296-300.

23. So B, Kim H, Lee S, Song H, Park J (2006) Novel bent-shaped liquid crystalline compounds: IV. Dimesogenic compounds containing 2-hydroxy-1,3-dioxypropylene and azobenzene mesogens. Dyes and Pigment 70(1): 38-42.

24. Tsai P, Wang I (2007) A facile synthesis of some new pyrazolo [1,5a] pyrimidine heterocyclic disazo dyes and an evaluation of their solvatochromic behaviour. Dyes and Pigment 74(3): 578-584.

25. Karcı F (2008) The synthesis and solvatochromic properties of some novel heterocyclic disazo dyes derived from barbituric acid. Dyes and Pigment 77(2): 451-456.

26. Yazdanbakhsh R, Mohammadi A, Abbasnia M (2010) Some heterocyclic azo dyes derived from thiazolyl derivatives; synthesis; substituent effects and solvatochromic studies. Spectrochim Acta A Mol Biomol Spectrosc 77(5): 1084-1087. 
27. Ucar M, Polatc K, Solak A, Toyc M, Aksu M (2010) The electrochemical behaviour of 2'-halogenated derivatives of 4-methoxyazobenzene at a mercury electrode. Dyes and Pigment 87(1): 55-61.

28. Wang D, He Y, Deng W, Wang X (2009) The photoinduced surface-reliefgrating formation behavior of side-chain azo polymers with narrow $\mathrm{Mr}$ distribution. Dyes and Pigment 82: 286-292.

29. Zollinger H (2003) Synthesis, Properties, and Applications of Organic Dyes and Pigments. Color chemistry $3^{\text {rd }}$ (Edn.), (Zurich: 27 Verlag Helvetica Chimia Acta, Wiley VCH.

30. Banerjee S (2016) Phenazines as chemosensors of solution analytes and as sensitizers in organic photovoltaics. ARKIVOC i: 82-110.

31. Richards G, Hill J P, Subbaiyan N, D’Souza F, Paul A, et al. (2009) Pyrazinacenes: Aza Analogues of Acenes. J Org Chem 74(23): 89148923.
32. Romanyuk AL, Polishchuk OP, Litvin BL (2002) Synthesis and Transformations of 2-Hydroxy-3-arylazo-1,4 naphthoquinones. Russ. J Gen Chem 72(2): 251-254.

33. Choudhary A, Patil S, Sekar (2016) Solvatochromism, halochromism, and azo hydrazone tautomerism in novel V-shaped azo-azine colorantsconsolidated experimental and computational approach. N Coloration Technology 132(5): 387-398.

34. Lee D, Jang K, Mcgrath K, Rycel U, Robins KA, et al. (2008) Single Component Organic Conductors Based on Neutral Radicals Containing the Pyrazino TCNQ Skeleton. Chem. Mater 20: 3688-3695.

\section{Your next submission with Juniper Publishers will reach you the below assets}

- Quality Editorial service

- Swift Peer Review

- Reprints availability

- E-prints Service

- Manuscript Podcast for convenient understanding

- Global attainment for your research

- Manuscript accessibility in different formats

( Pdf, E-pub, Full Text, Audio)

- Unceasing customer service

Track the below URL for one-step submission https://juniperpublishers.com/online-submission.php 